\title{
MCDA-based Approach to Sustainable Supplier Selection
}

\author{
Artur Karczmarczyk*, Jarosław Wątróbski ${ }^{\dagger}$, Grzegorz Ladorucki ${ }^{\dagger}$ and Jarosław Jankowski* \\ ${ }^{*}$ Faculty of Computer Science and Information Technology \\ West Pomeranian University of Technology in Szczecin, Żołnierska 49, 71-210 Szczecin, Poland \\ Email: \{artur.karczmarczyk,jaroslaw.jankowski\}@ zut.edu.pl \\ $\dagger$ Faculty of Economics and Management \\ University of Szczecin \\ Mickewicza 64, 71-101 Szczecin, Poland \\ Email: \{jwatrobski, gladorucki\}@wneiz.pl
}

\begin{abstract}
The process of sustainable supplier selection is crucial to a company's business continuity. Distortions in poorly chosen suppliers can lead to an impediment or even complete downtime of the company's operations. The paper proposes a new unique approach in which classical MCDA paradigm is extended with aspects of temporal evaluation and various temporal aggregation strategies are provided. The partial MCDA evaluations are performed with three MCDA methods - AHP, TOPSIS and COMET - to allow for hierarchical structuring of the decision problem, creation of a reference model and avoiding rank reversal. The proposed approach is verified on a case study with an actual company and its supplier selection from a group of 30 potential suppliers.
\end{abstract}

\section{INTRODUCTION}

$\mathbf{S}$ INCE the very beginning of the supply chain thinking, it has been understood that the selection of a proper supplier is the pillar of developing a competitive supply chain [1]. It is a strategic decision, which can considerably affect the company's competitive advantage [2]. The consequences of such decision can be intensified even further if a company plans expansion to new markets. A successful selection of decent suppliers can positively affect the company productivity and effectiveness, as well as decrease the operational costs [3]. Moreover, an apt arrangement of a supply base is crucial for effective and efficient materials and products logistics. Therefore, such selection directly affects the company's business continuity [2].

Integrated relationships between supply chain partners drive the supply chain efficiency, however, if over-dependence occurs, it might lead to propagation and amplification of various disruptions [4]. There are multiple works studying the negative effects of incompleteness or negligence of the supplier evaluation processes. In the early studies, Meade pointed out that wrong selection of suppliers can have negative effects on multiple processes within an organization [5], whereas the subsequent works expanded the negative consequences over the full integrated supply chain (Supply Chain Management - SCM) [6]. Moreover, Chan points out that the negligence of the process of suppliers evaluation can lead not only to disruptions in the supply chain process, but also to ceasing the primary operations of a company at all [6].
The development of the Internet and ICT (Information and Communication Technologies) lead to a considerable increase of the data processing efficiency. As a result, an on-going monitoring and evaluation of suppliers was made possible. Moreover, nowadays, such evaluation can easily be performed repeatedly over a span of time. The development of modern smart management information systems allowed the evaluation of suppliers on a temporal level, thus opening new research areas. From the methodological and practical points of view, an on-going monitoring - as opposed to a one-time evaluation - of the quality of services and products supplied by the company's key supply partners becomes an interesting research problem. Such evaluation takes into account an important, yet often overlooked, aspect of the appraisal changeability in time. For example, the businesses such as e-commerce websites can have as much as $30 \%$ of raise or loss in transactions count between the busy December and slow summer holiday months [7]. On the other hand, for the farming industry the summer months are the peak of the fruit picking season and the companies are looking for additional outsourcing suppliers to cope with the increased amount of work [8].

Over the span of the last two decades, the studies about environment protection have been increasingly gaining importance in the world [9]. The increased environmental awareness has lead to pressures from various stakeholders [10] for the companies to realize the significance of incorporating the green practices into their daily operations [11]. Therefore, the evaluation criteria used in the previous decades [2] needed to be expanded to support the evaluation of the green supply chain management (GSCM) practices [10], [12].

Multi-criteria decision analysis (MCDA) methods have been successfully applied in such evaluation problems to find "good" (but not optimal) solutions. However, the exclusive use of an MCDA method provides the "here and now" evaluation of the suppliers, yet it does not take into account the temporal validity of the aggregated data and the partial evaluations. The authors attempted to address this problem in their prior work (see [13]). However, the evaluations obtained with the most popular MCDA methods may be not fully reliable, because many of them are prone to the rank 
reversal phenomenon, which means that introduction of a new supplier to the evaluation process can reverse the ranks of the other, unrelated, suppliers. Therefore, the authors expand their approach presented in [13] and their contribution in this paper is to provide a framework for dynamic MCDA-based sustainable supplier selection, which takes into account the temporal aspects, the hierarchical structure of the decision problem, as well as it studies the full space of the decision problem, thus preventing the rank-reversal phenomenon. In practical terms, the introduction of the temporal aspects to the MCDA-based evaluation means introduction of a set of timeanchored MCDA-based models and providing the mechanisms of their aggregation according to the DM's needs.

The rest of this paper is organized as follows. In section 2 a literature review regarding the current state of art is provided. Section three presents the methodological framework. An empirical research and its results are presented in section four. The conclusions and future work directions are presented in section 5 .

\section{LITERATURE REVIEW}

The supplier selection is a process of a significant strategic importance for all the parties involved. The literature analysis provides a wide spectre of theoretical solutions and practical studies where the authors evaluate and select the suppliers in the supply chain. A numerous set of studies has been performed in the areas of electronics industry [10], [11], automotive [9], [15], [16], manufacturing [18], or food supply chain [17], [20] to name just a few.

Nowadays, due to the increased awareness of the environmental issues, the sustainable supplier development has become a necessity, as companies increasingly compete on the ground of having green supply chain capabilities [9]. Many companies struggle with the eco-friendly supplier selection, yet the advancements in the green supply chain management practice strategies can help in this selection [11]. The literature review of the research methodologies shows that the evaluation process is performed with the use of numerous analytical methods. A profound discussion of the approaches can be found in [21]. It can be also noted, that MCDA methods are becoming increasingly popular in such type of applications. Moreover, in some studies fuzzy variants of the crisp MCDA methods, as well as hybrid solutions are used.

Table I presents some of the recent applications of the MCDA methods in sustainable supplier selection. Kannan et al. [10] used the fuzzy TOPSIS method on a set of criteria based on green supply chain management (GSCM) practices to select green suppliers for a Brazilian electronics company. Similarly, Uppala et al. [11] used a hybrid approach of fuzzy AHP and fuzzy TOPSIS to select green suppliers for an Indian electronics company. For the same kind of industry in Taiwan, Chateterjee et al. [12] used a hybrid set of DEMATEL, ANP and MAIRCA methods with 15 criteria in 5 dimensions. Razaei et al. [2] used BWM (the Best-Worst Method) to evaluate 34 suppliers in edible oils industry for a company seeking to expand to a new country, whereas Banaeian et al.
[17] used the fuzzy variants of TOPSIS, VIKOR and GRA for a green supplier selection for an actual company from agri-food sector in Iran. Akman [9] used VIKOR and fuzzy cmeans clustering to evaluate 198 automotive industry suppliers in Turkey, based on 4 performance and 9 green criteria. Govindan et al. [20] used a mixture of Fuzzy TOPSIS, Fuzzy AHP and Fuzzy SAW for green supplier selection and order allocation in a low-carbon paper industry in India. A more comprehensive literature review of MCDA methods usage for the green supplier evaluation and selection can be found in [22], [23].

It is important to note, however, that the aforementioned MCDA-based approaches produce an assessment based on criteria measurements collected for a single moment in time. In case of the supplier selection problem, it is often required to consider the variability of each suppliers' evaluations in time. There have been some efforts to extend the MCDA methods to provide the ability to aggregate measurements and evaluations collected over a period of time. Banamar and De Smet [24] extended the PROMETHEE II method to allow temporal evaluations. Sahin and Mohamed [25] introduced a Spatial Temporal Decision framework, based upon a combination of System Dynamics modelling, Geographical Information Systems modeling and multi-criteria analyses of stakeholders' views with the use of the AHP method. Zhu and Hipel [26] used multiple stages grey target decision making method for vendor evaluation of a commercial airplane in China. Arasteh et al. [27] used the Goal Programming MCDA method to consider a 6-project portfolio over five investment periods and compared the use of their model in fuzzy and crisp scenarios. Last, but not least, a framework extending the TOPSIS method capabilities to evaluate and select green suppliers based on temporal analysis has been constructed [28], [13]. However, the latter approach still did not take into account the hierarchical structure of the decision problem, nor the rank reversal problem. Thus, the performed literature review allows to observe an interesting research gap of the sustainable suppliers selection problem which would simultaneously take into account the decision problem hierarchical structure, temporal aspects of the evaluation as well as protect the produced outcome from the rank reversal phenomenon.

\section{Methodological Framework}

The selection of a sustainable supplier in the Green Supplier Chain Management is a complex problem that requires a proper approach. The popular MCDA-based approaches are not without shortcomings. They are based on the classic MCDA paradigm, where constancy of all the elements of the decision support process is assumed. It should be noted, however, that the process of sustainable supplier evaluation requires taking into account its characteristics - its hierarchical structure as well as changeability of the appraisal elements in time. Based on the above, the authors propose using a complementary approach based on precise mapping of the structure of the decision problem (derived from AHP), building a supplier reference model (TOPSIS), as well as minimizing 
TABLE I

MCDA METHODS APPLICATION IN THE SUSTAINABLE SUPPLIER SELECTION PROBLEM

\begin{tabular}{|c|c|c|c|c|c|c|c|}
\hline Ref & MCDA Methods & Hybrid & Sens. Anal. & Application & Country & Criteria & Suppliers \\
\hline [14] & ANP, GRA & yes & no & automotive & Iran & 6 & 5 \\
\hline [15] & no & no & no & automotive & Malaysia & & 153 \\
\hline [16] & AHP & no & yes & automotive & Pakistan & 4 & 3 \\
\hline [9] & VIKOR, fuzzy c-means clustering & yes & no & automotive & Turkey & 13 & 198 \\
\hline [17] & Fuzzy TOPSIS, VIKOR, GRA & yes & no & edible oils & Iran & 4 & 10 \\
\hline [2] & BWM (best worst method) & no & no & edible oils & new country & 37 & 34 \\
\hline [10] & Fuzzy TOPSIS & no & yes & electronics & Brasil & GSCM & 12 \\
\hline [11] & Fuzzy AHP and Fuzzy Topsis & yes & no & electronics & India & GSCM & 10 \\
\hline \multirow[t]{2}{*}{ [12] } & DEMATEL, ANP, MAIRCA & yes & yes & electronics & Taiwan & 15 & \\
\hline & $\begin{array}{l}\text { Fuzzy TOPSIS, Fuzzy AHP, } \\
\text { Fuzzy SAW }\end{array}$ & yes & no & low-carbon paper & India & 5 & 4 \\
\hline [18] & Fuzzy AHP & no & yes & manufacturing & global & 25 & 2 \\
\hline [19] & $\begin{array}{l}\text { AHP, Fuzzy AHP, TOPSIS, } \\
\text { Fuzzy TOPSIS, IRP and } \\
\text { weighted IRP }\end{array}$ & yes & no & various & India, Germany, Switzerland & 24 & 41 \\
\hline
\end{tabular}

the shortcomings of the two methods by incorporating the COMET method. Moreover, the characteristics of the sustainable supplier evaluation process requires taking into account the variable effect of each supplier appraisal in a period of time. Therefore, the authors propose using time-conditioned evaluation aggregation strategies. The framework is visually presented on Fig. 1 and is described in detail in the following subsections.

\section{A. MCDA Foundations of the Proposed Framework}

The problem of sustainable supplier selection is a multicriteria problem, since it requires to take into consideration multiple, not only performance but also environmental, criteria. For example, Rezaei et al. [2] provided a list of 23 supplier selection criteria most utilised in the periods 19661990 and 1990-2001, and combined them with 15 modern environmental criteria. However, such a vast set of criteria makes the evaluation difficult to perform. Therefore, in the proposed approach we utilise the AHP method to organize the evaluation criteria in a hierarchy (see subsection III-B).

The AHP method produces a ranking of suppliers with the percentage score of the DM's preference of each supplier over the others. However, in the problem of sustainable supplier evaluation it would be beneficial not only to know how much one supplier is preferred over its competition, but also to compare such supplier with a potential ideal supplier. Therefore, the proposed framework utilizes the TOPSIS method to compute a potential ideal and anti-ideal supplier (see subsection III-C).

Unfortunately, neither the AHP nor the TOPSIS method are resistant to the rank reversal phenomenon. Therefore, in the last step of the MCDA analysis of the suppliers, the proposed approach explores the complete space of the decision problem criteria values, thus providing a universal solution immune to rank reversal (see subsection III-D).

Last, but not least, the outputs of the aforementioned three MCDA components of the framework constitute the input to the temporal aggregation (see subsection III-E).

\section{B. Hierarchical Structure of the Sustainable Supplier Selec- tion Problem}

The Analytical Hierarchy Process (AHP) by Saaty [30] is one of the best known and most widely used MCDA approaches. It is built on three main principles [31]: construction of a hierarchy, setting priorities and logical consistency. The decision problem is decomposed and structured into a hierarchy of sub-objectives, attributes, criteria and alternatives. In case of the proposed approach, the hierarchy of criteria is presented in Table II. Subsequently, the decision maker (DM) uses a pairwise comparison mechanism to determine the relative priority of each element at each level of the hierarchy. When comparing the elements of the hierarchy, a scale of $1-9$ is used to indicate the degree of preference of one element over the other. In case an element is less preferred, a reciprocal value is used, i.e. $\frac{1}{9}-1$.

The comparison results are stored in the pairwise comparison matrix, and the weights of individual elements are obtained. Each element of the matrix represents the dominance of an element in the column on the left over an element in the row on top. If the element on the left column is less important than the element in the row on top, a reciprocal value is inserted. The elements on the diagonal of the matrix are always 
TABLE II

EVALUATION CRITERIA GROUPED INTO CRITERIA, SUBCRITERIA AND SECOND LEVEL SUBCRITERIA

\begin{tabular}{|c|c|c|c|}
\hline Criteria & Subcriteria & 2 Level Subcriteria & Ref \\
\hline Cost & \multicolumn{2}{|c|}{$\begin{array}{l}\text { Product costs, Total supply cost which impact on final product, Financial cost, Operating expenditure, After- } \\
\text { sales costs, Sunk/loss cost/customer dissatisfaction, Suppliers production pauses } \\
\text { Product quality, Quality of Service, Warranty, Quality system certificate of the supplier, Quality assurance, }\end{array}$} & $\begin{array}{l}\text { [6], [9], [10], [14], [28], } \\
{[13]}\end{array}$ \\
\hline Quality & \multicolumn{2}{|c|}{$\begin{array}{l}\text { Conformance quality, Quality image, Vendor specific, Quality manual, Documentation control, Archive of } \\
\text { quality records, Receiving Inspection, Calibration control, Non-conforming material control system, Corrective } \\
\text { and preventive action system, Audit mechanism }\end{array}$} & [9], [11], [16], [13] \\
\hline Logistics & \multicolumn{2}{|c|}{$\begin{array}{l}\text { Choice of transportation, Reliability of quality, Delivery flexibility, Serious delivery delay rate, Compliance } \\
\text { delivery with quantity, Supplier Stock Management, Technology Level, Capability of R \& D, Order fulfill rate, } \\
\text { Capability of Product Development, Procurement, Return forecast for each client, Warehouse management, IT } \\
\text { management, Confirmed fill rate, Total order cycle time, System flexibility index, Integration technologies level, } \\
\text { Increment in market share }\end{array}$} & {$[6],[29],[21],[28]$} \\
\hline Social & \multicolumn{2}{|c|}{$\begin{array}{l}\text { The interests and rights of employee, The interests and the right of shareholders, Information disclosure, Expose } \\
\text { nonfinancial information, Respect for the policy, Discrimination in employment, Child labor } \\
\text { Customer base, Performance history, Production facility and capacity, Facility location, The number of working }\end{array}$} & $\begin{array}{l}{[9],[11],[18],[19],} \\
{[28],[13]}\end{array}$ \\
\hline Profile & \multicolumn{2}{|c|}{$\begin{array}{l}\text { years in this sector, References, Communication capability, The number of personnel, Education status of } \\
\text { the personnel, Machine capacity and capability, Manufacturing technology, Facilities manufacturing capacity, } \\
\text { Technical capability, Manufacturing planning capability, Handling and packaging capability } \\
\text { Green Technology Capabilities, Green Process/Production Planning, Recycling }\end{array}$} & [6], [17], [18], [13] \\
\hline \multirow[t]{8}{*}{ Green } & Innovation & $\begin{array}{l}\text { Product Design, Renewable Product Design, Green R \& D Project, Redesign } \\
\text { of Product }\end{array}$ & $\begin{array}{l}{[9],[29],[14],[18],} \\
{[28]}\end{array}$ \\
\hline & Environment protection & $\begin{array}{l}\text { Environment Efficiency, Eco-design, Environment Protection System Certifica- } \\
\text { tion, Environmental Protection policies/plans }\end{array}$ & $\begin{array}{l}{[29],[11],[12],[19],} \\
{[28],[13]}\end{array}$ \\
\hline & $\begin{array}{l}\text { Environment Manage- } \\
\text { ment }\end{array}$ & $\begin{array}{l}\text { Production of material ecologically efficient, Eco-design requirements for } \\
\text { energy using products, Level of restriction of hazardous substance in the } \\
\text { production process, Compliance with the local regulation and policies }\end{array}$ & [29], [14], [15], [28] \\
\hline & Pollution control & $\begin{array}{l}\text { Air Emissions, Waste water, Pollution Control Capability, Pollution Reduction } \\
\text { Capability }\end{array}$ & [9], [12], [19], [28] \\
\hline & $\begin{array}{l}\text { Hazardous Substance } \\
\text { Management }\end{array}$ & $\begin{array}{l}\text { Management of hazardous substances in the production procedure, Prevention } \\
\text { of mixed material, Process Auditing, Warehouse Management, Inventory of } \\
\text { Hazardous Substance }\end{array}$ & [29], [15], [22], [13] \\
\hline & Image & $\begin{array}{l}\text { Ratio of green customers to total customers, Green customers market share, } \\
\text { Stakeholders relationship, Green materials coding and recording }\end{array}$ & $\begin{array}{l}{[9],[11],[18],[28],} \\
{[13]}\end{array}$ \\
\hline & Product & $\begin{array}{l}\text { Recycle, Green Packaging, Cost of Component Disposal, Green Production, } \\
\text { Reuse, Re-Manufacture, Disposal }\end{array}$ & $\begin{array}{l}{[6],[12],[20],[22],} \\
{[28]}\end{array}$ \\
\hline & Materials & $\begin{array}{l}\text { Materials used in the supplied components that reduce the impact on natural } \\
\text { resources, Ability to alter process and product for reducing the impact on natural } \\
\text { resources }\end{array}$ & {$[13],[15],[19],[28]$,} \\
\hline
\end{tabular}

equal to 1 . Therefore, a total of $n(n-1) / 2$ comparisons needs to be performed. The procedure is repeated on all subsystems of the hierarchy. Sometimes, the DM's judgments can be inconsistent. However, in the AHP method, the inconsistency can be considered a tolerable error in measurement, as long as it does not exceed $10 \%$.

\section{Positive-Ideal and Negative-Ideal Supplier}

The TOPSIS method (Technique for Order Performance by Similarity to Ideal Solution) utilized in the proposed approach, is a popular MCDA decision-making technique, originally developed by Hwang and Yoon [32], based on the idea to compare relative the distances between the alternatives and the ideal (PIS, positive ideal solution) and anti-ideal solutions (NIS, negative ideal solution). The best alternative should be as close as possible to the PIS, and, at the same time, as far as possible from the NIS.

The algorithm of the TOPSIS method comprises of six stages. In the first of them, the decision maker (DM) is required to choose $m$ alternatives and $n$ criteria for use in solving the problem, which are used to build the decision matrix $D\left[x_{i j}\right]$. The rows of the matrix represent alternatives and the columns represent criteria. The $x_{i j}$ element is a representation of the decision attribute of the ith alternative regarding the jth criterion:

$$
D\left[x_{i j}\right]=\left(\begin{array}{ccccc}
x_{11} & x_{12} & x_{13} & \ldots & x_{1 n} \\
x_{21} & x_{22} & x_{23} & \ldots & x_{2 n} \\
x_{31} & x_{32} & x_{33} & \ldots & x_{3 n} \\
\ldots & \ldots & \ldots & \ldots & \ldots \\
x_{m 1} & x_{m 2} & x_{m 3} & \ldots & x_{m n}
\end{array}\right)
$$

The second step of the procedure is the decision matrix normalization. Each decision attribute is normalized separately for each criterion. The following formulae are used to normalize benefit and cost criteria respectively:

$$
r_{i j}=\frac{x_{i j}-\min _{i}\left(x_{i j}\right)}{\max _{i}\left(x_{i j}\right)-\min _{i}\left(x_{i j}\right)}
$$




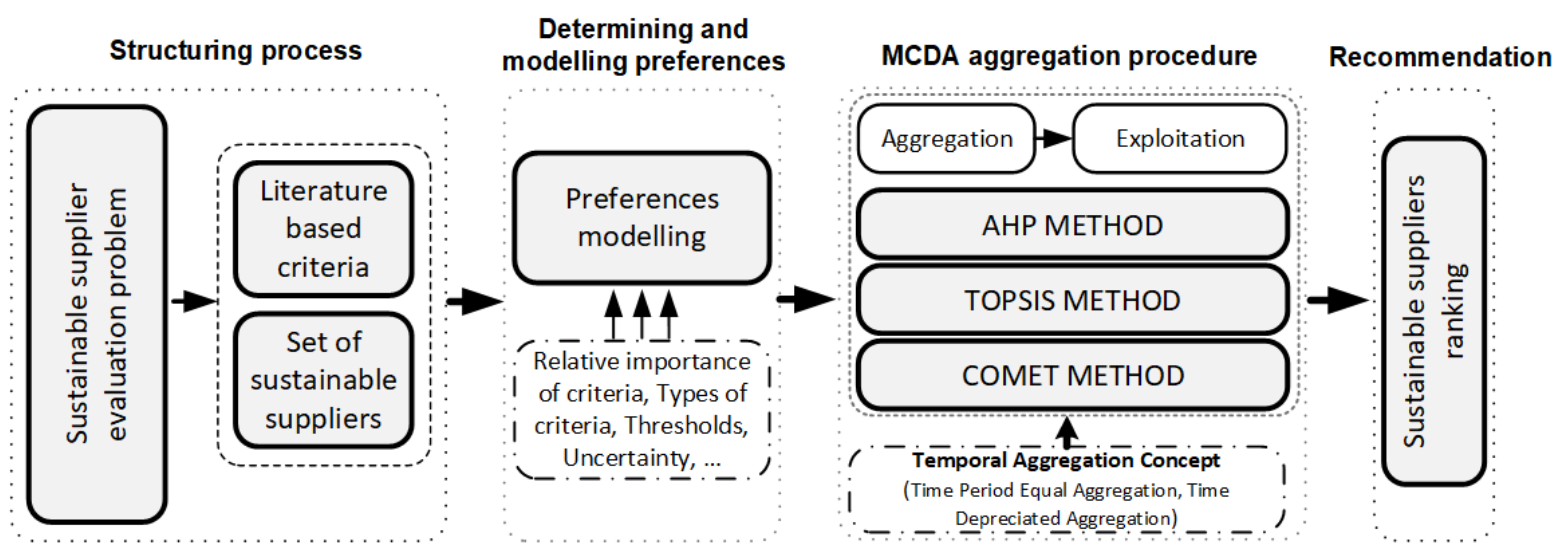

Fig. 1. Visual illustration of the proposed approach

$$
r_{i j}=\frac{\max _{i}\left(x_{i j}\right)-x_{i j}}{\max _{i}\left(x_{i j}\right)-\min _{i}\left(x_{i j}\right)}
$$

In the third step of the procedure, a weighted normalized decision matrix is created with the following formula:

$$
v_{i j}=w_{j} \cdot r_{i j}
$$

The PIS $\left(V_{J}^{+}\right)$and NIS $\left(V_{J}^{-}\right)$are obtained in the fourth step

$$
\begin{aligned}
& V_{j}^{+}=\left\{v_{1}^{+}, v_{2}^{+}, v_{3}^{+}, \ldots, v_{n}^{+}\right\} \\
& V_{j}^{-}=\left\{v_{1}^{-}, v_{2}^{-}, v_{3}^{-}, \ldots, v_{n}^{-}\right\}
\end{aligned}
$$

In the fifth step, the Euclidean distances between the alternatives and PIS and NIS are computed:

$$
\begin{aligned}
& D_{i}^{+}=\sqrt{\sum_{j=1}^{n}\left(v_{i j}-v_{j}^{+}\right)^{2}} \\
& D_{i}^{-}=\sqrt{\sum_{j=1}^{n}\left(v_{i j}-v_{j}^{-}\right)^{2}}
\end{aligned}
$$

In the last step of the algorithm, the relative closeness of the alternative to the ideal solution is calculated:

$$
C C_{i}=\frac{D_{i}^{-}}{D_{i}^{-}+D_{i}^{+}}
$$

Based on the $\mathrm{CCi}$ values, the final ranking of alternatives is created. In case of the proposed approach, the $\mathrm{CCi}$ value of each supplier allows to understand how far it is from a potential ideal supplier.

\section{Prevention of the Rank Reversal Phenomenon}

The proposed approach utilizes the Characteristic Objects METhod (COMET) [33] for exploring the complete space of possible solutions. The COMET method is based on the fuzzy sets theory and instead of comparing alternatives, as it is in AHP and TOPSIS, characteristic objects are created and compared in it, in order to create a linguistic rule base. Each evaluated alternative is subsequently scored in a defuzzification process. It is important to note, that due to the fact that a complete space of possible solutions of the decision problem has been explored by the comparisons of the problem's characteristic objects, introduction of a new supplier to the analysis will not change the evaluations of the remaining suppliers.

In the first step of the COMET procedure, the expert determines the dimensionality of the problem by selecting $r$ criteria, $C_{1}, C_{2}, \ldots, C_{r}$. Then, a set of fuzzy numbers is selected for each criterion $C_{i}$, e.g. $\left\{\tilde{C}_{i 1}, \tilde{C}_{i 2}, \ldots, \tilde{C}_{i c_{i}}\right\}$ (10):

$$
\begin{aligned}
& C_{1}=\left\{\tilde{C}_{11}, \tilde{C}_{12}, \ldots, \tilde{C}_{1 c_{1}}\right\} \\
& C_{1}=\left\{\tilde{C}_{21}, \tilde{C}_{22}, \ldots, \tilde{C}_{2 c_{2}}\right\} \\
& \ldots \\
& C_{r}=\left\{\tilde{C}_{r 1}, \tilde{C}_{r 2}, \ldots, \tilde{C}_{r c_{r}}\right\}
\end{aligned}
$$

where $c_{1}, c_{2}, \ldots, c_{r}$ are the ordinals of the fuzzy numbers for all criteria.

In the second step, characteristic objects $(C O)$ are obtained as a Cartesian product of the fuzzy numbers' cores of all the criteria (11):

$$
C O=C\left(C_{1}\right) \times C\left(C_{2}\right) \times \ldots \times C\left(C_{r}\right)
$$

As a result, an ordered set of all $C O$ is obtained (12):

$$
\begin{aligned}
& C O_{1}=C\left(\tilde{C}_{11}\right), C\left(\tilde{C}_{21}\right), \ldots, C\left(\tilde{C}_{r 1}\right) \\
& C O_{2}=C\left(\tilde{C}_{11}\right), C\left(\tilde{C}_{21}\right), \ldots, C\left(\tilde{C}_{r 2}\right) \\
& \ldots \\
& C O_{t}=C\left(\tilde{C}_{1 c_{1}}\right), C\left(\tilde{C}_{2 c_{2}}\right), \ldots, C\left(\tilde{C}_{r c_{r}}\right)
\end{aligned}
$$

where $t$ is the count of $C O$ s and is equal to (13): 


$$
t=\prod_{i=1}^{r} c_{i}
$$

In the third step of the procedure, the expert determines the Matrix of Expert Judgment $(M E J)$ by comparing the $C O \mathrm{~s}$ pairwise. The matrix is presented below:

$$
M E J=\left(\begin{array}{cccc}
\alpha_{11} & \alpha_{12} & \ldots & \alpha_{1 t} \\
\alpha_{21} & \alpha_{22} & \ldots & \alpha_{2 t} \\
\ldots & \ldots & \ldots & \ldots \\
\alpha_{t 1} & \alpha_{t 2} & \ldots & \alpha_{t t}
\end{array}\right)
$$

where $\alpha_{i j}$ is the result of comparing $C O_{i}$ and $C O_{j}$ by the expert. The function $f_{\text {exp }}$ denotes the mental judgment function of the expert. It depends solely on the knowledge of the expert. The expert's preferences can be presented as (15):

$$
\alpha_{i j}=\left\{\begin{array}{cc}
0.0, & f_{\exp }\left(C O_{i}\right)<f_{\text {exp }}\left(C O_{j}\right) \\
0.5, & f_{\exp }\left(C O_{i}\right)=f_{\text {exp }}\left(C O_{j}\right) \\
1.0, & f_{\exp }\left(C O_{i}\right)>f_{\text {exp }}\left(C O_{j}\right)
\end{array}\right.
$$

After the $M E J$ matrix is prepared, a vertical vector of the Summed Judgments $(S J)$ is obtained as follows (16).

$$
S J_{i}=\sum_{j=1}^{t} \alpha_{i j}
$$

Finally, the values of preference are approximated for each characteristic object. Correspondingly, a vertical vector $P$ is obtained, where the $i-t h$ row contains the approximate value of preference for $C \mathrm{O}_{i}$.

Then, in the fourth step, each characteristic object and its value of preference is converted to a fuzzy rule as follows (17):

$$
\begin{array}{llllllll}
I F & C\left(\tilde{C}_{1 i}\right) & A N D & C\left(\tilde{C}_{2 i}\right) & A N D & \ldots & \text { THEN } & P_{i}
\end{array}
$$

Thus, a complete fuzzy rule base is obtained.

Eventually, in the final step, each alternative is presented as a set of crisp numbers, e.g., $A_{i}=\left\{a_{1 i}, a_{2 i}, \ldots, a_{r i}\right\}$. This set corresponds to the criteria $C_{1}, C_{2}, \ldots, C_{r}$. Mamdani's fuzzy inference method is used to compute the preference of the $i-t h$ alternative.

\section{E. Temporal Aggregation of the Supplier Evaluation Results}

The classic MCDA procedure requires both the alternatives and criteria to be constant [34], [35]. However, if criteria measurements are collected over a span of time, the ones closest to the time of the evaluation are intuitively the most valid. By all means, the criteria measurements from all periods can be aggregated using for example fuzzy sets theory and fuzzy numbers. However, it would affect the accuracy of the evaluation method input data and, consequently, could lead to oversimplifying the model and reducing the quality of the decision support. Therefore, in the proposed approach, instead of aggregating the input data, the DM should perform a temporal aggregation of the outcomes produced by evaluations produced in each period.

The temporal aggregation concept is based on the construction of a general utility function with an additional attribute called forgetting. Two possible types of forgetting strategies can be used:

TPEA

Time Period Equal Aggregation - the impact of individual ratings on the final outcome of the assessment is balanced;

TDA

Time Depreciated Aggregation - along with increasing distance of the historical data to the current period, its significance is being diminished.

Regardless of the forgetting strategies chosen, the general utility of a supplier can be obtained with the formula:

$$
V\left(a^{i}\right)=\sum_{k=1}^{n} S_{i k} \cdot p\left(t_{k}\right)
$$

where $V\left(a^{i}\right)$ denotes the general utility for the ith supplier on the basis of all $n$ periods taken into consideration, $S_{i k}$ means the utility of the ith supplier in period $k$ and $p\left(t_{k}\right)$ means the significance of data for the $k$ period in time $t$, based on the selected forgetting strategy. $S_{i k}$ is determined in the previous step by the AHP, TOPSIS and COMET methods.

\section{EMPIRICAL RESEARCH}

The proposed approach was empirically verified on a real company. A set of thirty suppliers of the company were selected for the research. The suppliers for the research were selected based on the yearly and monthly turnover. The criteria for the study were chosen as a result of a thorough literature review and are presented in Table II. The companies' performances in some of the criteria, such as time to confirm delivery, delivery time, delivery on-time, complaints, turnover, cost of transport, terms of payment and currency were fetched automatically from ERP systems, whereas for criteria where automation was not possible, surveys and expert judgment were utilized.

The obtained measurements of each criterion were normalized and mapped according to the Likert scale. In the next step, the AHP, TOPSIS and COMET methods were used to obtain the utility values of each supplier for each period. Eventually, temporal aggregation was performed based on five strategies TPEA, TDA1, TDA2, TDA3 and TDA4, which are illustrated in Table III and Fig 2.

In case of the TPEA strategy, the $p\left(t_{k}\right)$ value is always equal 1 . In case of TDA1, TDA2 and TDA 3 the forgetting 


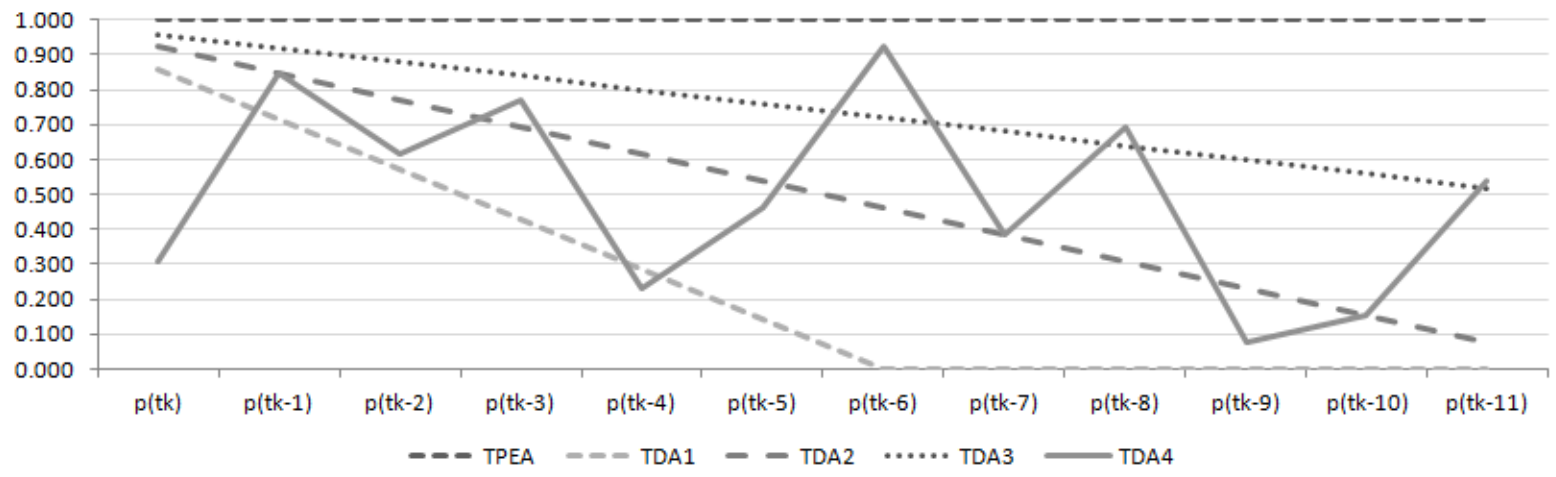

Fig. 2. Forgetting functions for TPEA, TDA1, TDA2, TDA3 and TDA4 strategies

TABLE III

FORGETTING FUNCTION PARAMETERS FOR TPEA, TDA1, TDA2, TDA3 AND TDA4 STRATEGIES

\begin{tabular}{|c|c|c|c|c|c|c|c|c|c|c|c|c|}
\hline Aggregation & $\mathbf{p}(\mathbf{t k})$ & $\mathbf{p}(\mathbf{t k - 1})$ & $p(t k-2)$ & $p(t k-3)$ & $p(t k-4)$ & $p(t k-5)$ & $p($ tk-6) & $\mathbf{p}(\mathrm{tk}-7)$ & $\mathbf{p}(\mathbf{t k - 8})$ & p(tk-9) & $p(t k-10)$ & $p(t k-11)$ \\
\hline TPEA & 1.000 & 1.000 & 1.000 & 1.000 & 1.000 & 1.000 & 1.000 & 1.000 & 1.000 & 1.000 & 1.000 & 1.000 \\
\hline TDA1 & 0.857 & 0.714 & 0.571 & 0.429 & 0.286 & 0.143 & 0.000 & 0.000 & 0.000 & 0.000 & 0.000 & 0.000 \\
\hline TDA2 & 0.923 & 0.846 & 0.769 & 0.692 & 0.615 & 0.538 & 0.462 & 0.385 & 0.308 & 0.231 & 0.154 & 0.077 \\
\hline TDA3 & 0.960 & 0.920 & 0.880 & 0.840 & 0.800 & 0.760 & 0.720 & 0.680 & 0.640 & 0.600 & 0.560 & 0.520 \\
\hline TDA4 & 0.308 & 0.846 & 0.615 & 0.769 & 0.231 & 0.462 & 0.923 & 0.385 & 0.692 & 0.077 & 0.154 & 0.538 \\
\hline
\end{tabular}

function is spread over 6, 12 and 24 months respectively. In case of TDA4, the value of the forgetting function depends on the supplies turnover.

The results of the temporal evaluation of the suppliers based on the AHP, TOPSIS and COMET methods partial evaluations are presented in Tables IV, V and VI respectively. For the reasons of brevity, the number of suppliers presented in the paper was limited to twelve.

As it can be noticed from the analysis of Fig. 3, all obtained rankings are highly correlated. A higher correlation can be observed between the rankings produced by the same method. However, the rankings obtained based on the AHP or TOPSIS methods are more correlated than any of these methods with the COMET method. This is caused by the fact that the COMET method explores the complete space of the decision problem, whereas the AHP and TOPSIS methods operate locally on the provided alternatives (suppliers).

The analysis of the temporal evaluation of the suppliers based on the three MCDA methods allowed to observe that depending on the aggregation strategy and the MCDA method used, the ranks of the suppliers vary slightly. However, it was noticed that the supplier A12 appeared on the majority of the rankings within the group of the best 5 suppliers.

\section{Conclusions}

The process of sustainable supplier selection is crucial to the companies' business continuity. Distortions in invalidly chosen suppliers can lead to a considerable impediment or even to a complete cease of company's operations. The current research focus is double-track. The first track focuses on the evaluation methods development. The second one focuses on the sustainability factors of the green cities, taking into account not only greening, but also human well being. While many prior studies focused on evaluation of suppliers based on performance and environmental criteria, the approach presented in this paper extended them with the following authors' contributions:

- possibility to organize the evaluation criteria into a multilevel hierarchy for better manageability of the decision problem;

- possibility to obtain a potential positive-ideal and negative-ideal supplier description and evaluation of the actual suppliers in relation to those two test cases;

- possibility to comprehensively explore the complete space of solutions of the sustainable supplier selection decision problem, thus preventing reversals in the produced rankings;

- possibility of temporal aggregation of the rankings obtained over a span of time with various forgetting strategies.

Compared to study [13], the performed research clearly shows that usage of a single hierarchical MCDA method in the process of sustainable supplier selection might not always be sufficient if the exploration of the complete space of the selection problem solutions or potential positive-ideal and negative-ideal supplier descriptions are needed. 
TABLE IV

TEMPORAL EVALUATION OF 12 OF THE SUPPLIERS BASED ON THE AHP METHOD OUTPUT

\begin{tabular}{lllllllllll}
\hline Supplier & \multicolumn{3}{c}{ Supplier Temporal Evaluation $\left(V\left(a_{i}\right)\right)$} & \multicolumn{5}{c}{ Supplier Ranking in Temporal Evaluation } \\
\hline $\mathrm{Ai}$ & TPEA & TDA1 & TDA2 & TDA3 & TDA4 & TPEA & TDA1 & TDA2 & TDA3 & TDA4 \\
\hline A1 & 0.3277 & 0.0825 & 0.1634 & 0.2422 & 0.1646 & 21 & 23 & 24 & 23 & 25 \\
$\mathrm{~A} 2$ & 0.3544 & 0.0891 & 0.1782 & 0.2628 & 0.177 & 15 & 17 & 16 & 15 & 16 \\
$\mathrm{~A} 3$ & 0.4262 & 0.1067 & 0.2123 & 0.315 & 0.2103 & 12 & 12 & 12 & 12 & 12 \\
$\mathrm{~A} 4$ & 0.3971 & 0.1001 & 0.1978 & 0.2934 & 0.1982 & 14 & 14 & 14 & 14 & 14 \\
$\mathrm{~A} 5$ & 0.4847 & 0.1181 & 0.2399 & 0.3574 & 0.2418 & 4 & 5 & 5 & 4 & 4 \\
$\mathrm{~A} 6$ & 0.4709 & 0.1179 & 0.2361 & 0.3488 & 0.234 & 6 & 6 & 6 & 6 & 7 \\
$\mathrm{~A} 7$ & 0.2488 & 0.0701 & 0.1347 & 0.1894 & 0.1331 & 29 & 27 & 29 & 29 & 29 \\
$\mathrm{~A} 8$ & 0.454 & 0.1149 & 0.2302 & 0.3376 & 0.2298 & 8 & 9 & 8 & 8 & 9 \\
$\mathrm{~A} 9$ & 0.5059 & 0.1323 & 0.2585 & 0.3773 & 0.2531 & 3 & 1 & 2 & 3 & 3 \\
$\mathrm{~A} 10$ & 0.4325 & 0.1086 & 0.2174 & 0.3207 & 0.2172 & 10 & 11 & 11 & 11 & 11 \\
$\mathrm{~A} 11$ & 0.3308 & 0.0843 & 0.1662 & 0.2452 & 0.1664 & 19 & 22 & 22 & 22 & 23 \\
$\mathrm{~A} 12$ & 0.5136 & 0.1257 & 0.2552 & 0.3792 & 0.2571 & 2 & 3 & 3 & 2 & 2 \\
\hline
\end{tabular}

TABLE $\mathrm{V}$

TEMPORAL EVALUATION OF 12 OF THE SUPPLIERS BASED ON THE TOPSIS METHOD OUTPUT

\begin{tabular}{lllllllllll}
\hline Supplier & \multicolumn{3}{c}{ Supplier Temporal Evaluation $\left(V\left(a_{i}\right)\right)$} & \multicolumn{5}{c}{ Supplier Ranking in Temporal Evaluation } \\
\hline $\mathrm{Ai}$ & TPEA & TDA1 & TDA2 & TDA3 & TDA4 & TPEA & TDA1 & TDA2 & TDA3 & TDA4 \\
\hline A1 & 7.4096 & 1.892 & 3.7341 & 5.4983 & 3.7436 & 15 & 17 & 17 & 16 & 16 \\
A2 & 7.5508 & 1.9118 & 3.8349 & 5.6185 & 3.7822 & 13 & 16 & 13 & 13 & 14 \\
A3 & 7.6704 & 1.9496 & 3.8679 & 5.6931 & 3.8418 & 11 & 14 & 12 & 12 & 13 \\
A4 & 7.1932 & 1.802 & 3.5955 & 5.3224 & 3.5904 & 17 & 20 & 18 & 17 & 18 \\
A5 & 8.6405 & 2.1266 & 4.3261 & 6.397 & 4.378 & 7 & 7 & 7 & 7 & 6 \\
A6 & 8.9969 & 2.2919 & 4.5817 & 6.701 & 4.4994 & 2 & 3 & 3 & 2 & 4 \\
A7 & 5.5666 & 1.5739 & 3.014 & 4.2392 & 2.9679 & 29 & 25 & 27 & 29 & 28 \\
A8 & 7.4461 & 1.931 & 3.8171 & 5.559 & 3.7492 & 14 & 15 & 15 & 14 & 15 \\
A9 & 8.9034 & 2.3761 & 4.6095 & 6.6706 & 4.5037 & 3 & 1 & 2 & 3 & 3 \\
A10 & 8.2315 & 2.0806 & 4.1645 & 6.1167 & 4.1403 & 8 & 8 & 8 & 8 & 8 \\
A11 & 6.9282 & 1.8095 & 3.5188 & 5.1553 & 3.475 & 19 & 19 & 20 & 20 & 21 \\
A12 & 9.0961 & 2.3101 & 4.6211 & 6.7691 & 4.5967 & 1 & 2 & 1 & 1 & 1
\end{tabular}

The research has identified possible areas of improvement and future work directions. The presented approach is only a framework which requires further verification in a complete data space, expanding the presented case study.

\section{REFERENCES}

[1] R. R. Colton, Industrial Purchasing: Principles and Practices. CE Merrill, 1962.

[2] J. Rezaei, T. Nispeling, J. Sarkis, and L. Tavasszy, "A supplier selection life cycle approach integrating traditional and environmental criteria using the best worst method," Journal of Cleaner Production, vol. 135, pp. 577-588, Nov. 2016. doi: 10.1016/j.jclepro.2016.06.125. [Online]. Available: http://www.sciencedirect.com/science/article/pii/S0959652616308022

[3] R. Khodaverdi and L. Olfat, "A fuzzy medm approach for supplier selection and evaluation: a case study in an automobile manufacturing company," in 2011 IEEE International Conference on Industrial Engineering and Engineering Management, 2011, pp. 25-27.
[4] A. Świerczek, "The impact of supply chain integration on the "snowball effect" in the transmission of disruptions: An empirical evaluation of the model," International Journal of Production Economics, vol. 157, pp. 89-104, Nov. 2014. doi: 10.1016/j.ijpe.2013.08.010. [Online]. Available: http://www.sciencedirect.com/science/article/pii/S0925527313003654

[5] L. Meade and J. Sarkis, "Strategic analysis of logistics and supply chain management systems using the analytical network process 1this work was partially supported by NSF Grants 9320949 and 9505967, and Texas Higher Education Coordinating Board ATP Grant Number 003656-036.1," Transportation Research Part E: Logistics and Transportation Review, vol. 34, no. 3, pp. 201-215, Sep. 1998. doi: 10.1016/S1366-5545(98)00012-X. [Online]. Available: http://www.sciencedirect.com/science/article/pii/S136655459800012X

[6] F. T. S. Chan and N. Kumar, "Global supplier development considering risk factors using fuzzy extended AHP-based approach," Omega, vol. 35, no. 4, pp. 417-431, Aug. 2007. doi: 10.1016/j.omega.2005.08.004. [Online]. Available: http://www.sciencedirect.com/science/article/pii/S030504830500112X

[7] T. Grant, "10 Ways to Drive E-Commerce Sales During Slow Online Shopping Months." [Online]. 
TABLE VI

TEMPORAL EVALUATION OF 10 OF THE SUPPLIERS BASED ON THE COMET METHOD OUTPUT

\begin{tabular}{lllllllllll}
\hline Supplier & \multicolumn{1}{l}{ Supplier } & Temporal Evaluation $\left(V\left(a_{i}\right)\right.$ & \multicolumn{6}{c}{ Supplier Ranking in Temporal Evaluation } \\
\hline Ai & TPEA & TDA1 & TDA2 & TDA3 & TDA4 & TPEA & TDA1 & TDA2 & TDA3 & TDA4 \\
\hline A1 & 9.0881 & 2.329 & 4.5962 & 6.7523 & 4.6717 & 5 & 2 & 2 & 4 & 2 \\
A2 & 8.9049 & 2.2777 & 4.5325 & 6.6312 & 4.5816 & 8 & 7 & 6 & 7 & 5 \\
A3 & 8.6651 & 2.2267 & 4.3968 & 6.4456 & 4.4126 & 11 & 11 & 11 & 12 & 10 \\
A4 & 8.9418 & 2.2138 & 4.4665 & 6.6146 & 4.5174 & 7 & 13 & 9 & 8 & 8 \\
A5 & 9.1468 & 2.2858 & 4.5789 & 6.7715 & 4.5951 & 3 & 5 & 4 & 3 & 3 \\
A6 & 9.4306 & 2.3692 & 4.7489 & 6.9961 & 4.7525 & 1 & 1 & 1 & 1 & 1 \\
A7 & 5.6706 & 1.6237 & 3.0464 & 4.306 & 3.0743 & 29 & 25 & 29 & 29 & 28 \\
A8 & 8.6468 & 2.2358 & 4.4163 & 6.4469 & 4.3546 & 12 & 9 & 10 & 11 & 13 \\
A9 & 8.6993 & 2.215 & 4.389 & 6.4579 & 4.37 & 10 & 12 & 12 & 10 & 12 \\
A10 & 8.513 & 2.1355 & 4.2691 & 6.3062 & 4.2833 & 15 & 16 & 14 & 15 & 14 \\
A11 & 7.1745 & 1.8728 & 3.6351 & 5.334 & 3.6209 & 21 & 24 & 24 & 23 & 25 \\
A12 & 9.1024 & 2.2848 & 4.5677 & 6.7444 & 4.5695 & 4 & 6 & 5 & 5 & 6
\end{tabular}

\begin{tabular}{|c|c|c|c|c|c|c|c|c|c|c|c|c|c|c|c|}
\hline & $\begin{array}{c}\text { TPEA - } \\
\text { AHP }\end{array}$ & $\begin{array}{c}\text { TDA1 - } \\
\text { AHP }\end{array}$ & $\begin{array}{c}\text { TDA2 - } \\
\text { AHP }\end{array}$ & $\begin{array}{c}\text { TDA3 - } \\
\text { AHP }\end{array}$ & $\begin{array}{c}\text { TDA4 - } \\
\text { AHP }\end{array}$ & $\begin{array}{l}\text { TPEA - } \\
\text { TOPSIS }\end{array}$ & $\begin{array}{l}\text { TDA1 - } \\
\text { TOPSIS }\end{array}$ & $\begin{array}{l}\text { TDA2 - } \\
\text { TOPSIS }\end{array}$ & $\begin{array}{l}\text { TDA3 - } \\
\text { TOPSIS }\end{array}$ & $\begin{array}{l}\text { TDA4 - } \\
\text { TOPSIS }\end{array}$ & $\begin{array}{l}\text { TPEA - } \\
\text { COMET }\end{array}$ & $\begin{array}{l}\text { TDA1 - } \\
\text { COMET }\end{array}$ & $\begin{array}{l}\text { TDA2 - } \\
\text { COMET }\end{array}$ & $\begin{array}{l}\text { TDA3 - } \\
\text { COMET }\end{array}$ & $\begin{array}{l}\text { TDA4 - } \\
\text { COMET }\end{array}$ \\
\hline $\begin{array}{c}\text { TPEA - } \\
\text { AHP }\end{array}$ & 1.000 & 0.937 & 0.959 & 0.980 & 0.959 & 0.926 & 0.847 & 0.909 & 0.921 & 0.926 & 0.828 & 0.762 & 0.795 & 0.810 & 0.783 \\
\hline $\begin{array}{c}\text { TDA1 - } \\
\text { AHP }\end{array}$ & 0.937 & 1.000 & 0.986 & 0.975 & 0.947 & 0.875 & 0.902 & 0.913 & 0.899 & 0.895 & 0.762 & 0.788 & 0.772 & 0.774 & 0.737 \\
\hline $\begin{array}{c}\text { TDA2 - } \\
\text { AHP }\end{array}$ & 0.959 & 0.986 & 1.000 & 0.990 & 0.977 & 0.887 & 0.895 & 0.919 & 0.911 & 0.919 & 0.760 & 0.757 & 0.767 & 0.766 & 0.737 \\
\hline $\begin{array}{c}\text { TDA3 - } \\
\text { AHP }\end{array}$ & 0.980 & 0.975 & 0.990 & 1.000 & 0.977 & 0.904 & 0.877 & 0.920 & 0.919 & 0.927 & 0.794 & 0.771 & 0.792 & 0.794 & 0.769 \\
\hline $\begin{array}{c}\text { TDA4 - } \\
\text { AHP }\end{array}$ & 0.959 & 0.947 & 0.977 & 0.977 & 1.000 & 0.851 & 0.828 & 0.874 & 0.868 & 0.917 & 0.732 & 0.706 & 0.730 & 0.726 & 0.735 \\
\hline $\begin{array}{l}\text { TPEA - } \\
\text { TOPSIS }\end{array}$ & 0.926 & 0.875 & 0.887 & 0.904 & 0.851 & 1.000 & 0.932 & 0.979 & 0.993 & 0.957 & 0.881 & 0.799 & 0.846 & 0.869 & 0.812 \\
\hline $\begin{array}{l}\text { TDA1 - } \\
\text { TOPSIS }\end{array}$ & 0.847 & 0.902 & 0.895 & 0.877 & 0.828 & 0.932 & 1.000 & 0.976 & 0.957 & 0.936 & 0.761 & 0.767 & 0.773 & 0.778 & 0.715 \\
\hline $\begin{array}{l}\text { TDA2 - } \\
\text { TOPSIS }\end{array}$ & 0.909 & 0.913 & 0.919 & 0.920 & 0.874 & 0.979 & 0.976 & 1.000 & 0.994 & 0.971 & 0.828 & 0.792 & 0.822 & 0.834 & 0.783 \\
\hline $\begin{array}{l}\text { TDA3 - } \\
\text { TOPSIS }\end{array}$ & 0.921 & 0.899 & 0.911 & 0.919 & 0.868 & 0.993 & 0.957 & 0.994 & 1.000 & 0.967 & 0.857 & 0.798 & 0.840 & 0.855 & 0.800 \\
\hline $\begin{array}{l}\text { TDA4 - } \\
\text { TOPSIS }\end{array}$ & 0.926 & 0.895 & 0.919 & 0.927 & 0.917 & 0.957 & 0.936 & 0.971 & 0.967 & 1.000 & 0.816 & 0.768 & 0.810 & 0.812 & 0.806 \\
\hline $\begin{array}{l}\text { TPEA - } \\
\text { COMET }\end{array}$ & 0.828 & 0.762 & 0.760 & 0.794 & 0.732 & 0.881 & 0.761 & 0.828 & 0.857 & 0.816 & 1.000 & 0.930 & 0.975 & 0.993 & 0.960 \\
\hline $\begin{array}{l}\text { TDA1 - } \\
\text { COMET }\end{array}$ & 0.762 & 0.788 & 0.757 & 0.771 & 0.706 & 0.799 & 0.767 & 0.792 & 0.798 & 0.768 & 0.930 & 1.000 & 0.972 & 0.953 & 0.947 \\
\hline $\begin{array}{l}\text { TDA2 - } \\
\text { COMET }\end{array}$ & 0.795 & 0.772 & 0.767 & 0.792 & 0.730 & 0.846 & 0.773 & 0.822 & 0.840 & 0.810 & 0.975 & 0.972 & 1.000 & 0.989 & 0.978 \\
\hline $\begin{array}{l}\text { TDA3 - } \\
\text { COMET }\end{array}$ & 0.810 & 0.774 & 0.766 & 0.794 & 0.726 & 0.869 & 0.778 & 0.834 & 0.855 & 0.812 & 0.993 & 0.953 & 0.989 & 1.000 & 0.965 \\
\hline $\begin{array}{l}\text { TDA4 - } \\
\text { COMET }\end{array}$ & 0.783 & 0.737 & 0.737 & 0.769 & 0.735 & 0.812 & 0.715 & 0.783 & 0.800 & 0.806 & 0.960 & 0.947 & 0.978 & 0.965 & 1.000 \\
\hline
\end{tabular}

Fig. 3. Correlation matrix between AHP, TOPSIS and COMET evaluations rankings based on TPEA, TDA1, TDA2, TDA3 and TDA4 forgetting strategies

Available: https://www.infusionsoft.com/business-success-blog/sales/ e-commerce/10-ways-to-drive-e-commerce-sales-during-slow-months

[8] "Broadwater Farm - Summer Fruit Picking - The Job and Pay." [Online]. Available: https://www.broadwaterfarm.biz/summer-fruit-picking-uk/

[9] G. Akman, "Evaluating suppliers to include green supplier development programs via fuzzy c-means and VIKOR methods," Computers \& Industrial Engineering, vol. 86, pp. 69-82, Aug. 2015. doi: 10.1016/j.cie.2014.10.013. [Online]. Available: http://www.sciencedirect.com/science/article/pii/S0360835214003441

[10] D. Kannan, A. B. L. d. S. Jabbour, and C. J. C. Jabbour, "Selecting green suppliers based on GSCM practices: Using fuzzy TOPSIS applied to a Brazilian electronics company," European Journal of Operational Research, vol. 233, no. 2, pp. 432447, Mar. 2014. doi: 10.1016/j.ejor.2013.07.023. [Online]. Available:
http://www.sciencedirect.com/science/article/pii/S0377221713006048

[11] A. K. Uppala, R. Ranka, J. J. Thakkar, M. V. Kumar, and S. Agrawal, "Selection of Green Suppliers Based on GSCM Practices: Using Fuzzy MCDM Approach in an Electronics Company," Handbook of Research on Fuzzy and Rough Set Theory in Organizational Decision Making, pp. 355-375, 2017. doi: 10.4018/978-1-52251008-6.ch016. [Online]. Available: https://www.igi-global.com/chapter/ selection-of-green-suppliers-based-on-gscm-practices/169495

[12] K. Chatterjee, D. Pamucar, and E. K. Zavadskas, "Evaluating the performance of suppliers based on using the R'AMATELMAIRCA method for green supply chain implementation in electronics industry," Journal of Cleaner Production, vol. 184, pp. 101-129, May 2018. doi: 10.1016/j.jclepro.2018.02.186. [Online]. Available: http://www.sciencedirect.com/science/article/pii/S0959652618305055 
[13] J. Wątróbski, W. Sałabun, and G. Ladorucki, "The Temporal Supplier Evaluation Model Based on Multicriteria Decision Analysis Methods," in Intelligent Information and Database Systems, N. T. Nguyen, S. Tojo, L. M. Nguyen, and B. Trawiński, Eds. Cham: Springer International Publishing, 2017, vol. 10191, pp. 432-442 ISBN 978-3-319-54471-7 978-3-319-54472-4. [Online]. Available: http://link.springer.com/10.1007/978-3-319-54472-4_41

[14] S. H. Hashemi, A. Karimi, and M. Tavana, "An integrated green supplier selection approach with analytic network process and improved Grey relational analysis," International Journal of Production Economics, vol. 159, pp. 178-191, Jan. 2015. doi: 10.1016/j.ijpe.2014.09.027. [Online]. Available: http://www.sciencedirect.com/science/article/pii/S0925527314003053

[15] S. Zailani, K. Govindan, M. Iranmanesh, M. R. Shaharudin, and Y. Sia Chong, "Green innovation adoption in automotive supply chain the Malaysian case," Journal of Cleaner Production, vol. 108, pp. 11151122, Dec. 2015. doi: 10.1016/j.jclepro.2015.06.039. [Online]. Available: http://linkinghub.elsevier.com/retrieve/pii/S0959652615007684

[16] F. Dweiri, S. Kumar, S. A. Khan, and V. Jain, "Designing an integrated AHP based decision support system for supplier selection in automotive industry," Expert Systems with Applications, vol. 62, pp. 273-283, Nov. 2016. doi: 10.1016/j.eswa.2016.06.030. [Online]. Available: http://www.sciencedirect.com/science/article/pii/S0957417416303104

[17] N. Banaeian, H. Mobli, B. Fahimnia, I. E. Nielsen, and M. Omid, "Green supplier selection using fuzzy group decision making methods: A case study from the agri-food industry," Computers \& Operations Research, vol. 89, pp. 337-347, Jan. 2018. doi: 10.1016/j.cor.2016.02.015. [Online]. Available: http://www.sciencedirect.com/science/article/pii/S0305054816300399

[18] S. Gold and A. Awasthi, "Sustainable global supplier selection extended towards sustainability risks from $(1+n)$ th tier suppliers using fuzzy AHP based approach," IFAC-PapersOnLine, vol. 48, no. 3, pp. 966971, Jan. 2015. doi: 10.1016/j.ifacol.2015.06.208. [Online]. Available: http://www.sciencedirect.com/science/article/pii/S2405896315004474

[19] H. Kaur, S. P. Singh, and R. Glardon, "An Integer Linear Program for Integrated Supplier Selection: A Sustainable Flexible Framework," Global Journal of Flexible Systems Management, vol. 17, no. 2 , pp. 113-134, Jun. 2016. doi: 10.1007/s40171-015-0105-1. [Online]. Available: https://link.springer.com/article/10.1007/s40171-015-0105-1

[20] K. Govindan and R. Sivakumar, "Green supplier selection and order allocation in a low-carbon paper industry: integrated multi-criteria heterogeneous decision-making and multi-objective linear programming approaches," Annals of Operations Research, vol. 238, no. 1-2, pp. 243-276, Mar. 2016. doi: 10.1007/s10479-015-2004-4. [Online]. Available: https://link.springer.com/article/10.1007/s10479-015-2004-4

[21] C.-H. Wang, "Using quality function deployment to conduct vendor assessment and supplier recommendation for business-intelligence systems," Computers \& Industrial Engineering, vol. 84, pp. 2431, Jun. 2015. doi: 10.1016/j.cie.2014.10.005. [Online]. Available: http://www.sciencedirect.com/science/article/pii/S0360835214003362

[22] K. Govindan, S. Rajendran, J. Sarkis, and P. Murugesan, "Multi criteria decision making approaches for green supplier evaluation and selection: a literature review," Journal of Cleaner Production, vol. 98, pp. 66-83, Jul. 2015. doi: 10.1016/j.jclepro.2013.06.046. [Online]. Available: http://www.sciencedirect.com/science/article/pii/S095965261300437X

[23] J. Wątróbski, "Outline of Multicriteria Decision-making in Green Logistics," Transportation Research Procedia, vol. 16, pp. 537552, Jan. 2016. doi: 10.1016/j.trpro.2016.11.051. [Online]. Available: http://www.sciencedirect.com/science/article/pii/S2352146516306652
[24] I. Banamar and Y. De Smet, "An extension of promethee ii to temporal evaluations code-smg-technical report series," 2016.

[25] O. Sahin and S. Mohamed, "A spatial temporal decision framework for adaptation to sea level rise," Environmental Modelling \& Software, vol. 46, pp. 129-141, Aug. 2013. doi: 10.1016/j.envsoft.2013.03.004. [Online]. Available: http://linkinghub.elsevier.com/retrieve/pii/S1364815213000558

[26] J. Zhu and K. W. Hipel, "Multiple stages grey target decision making method with incomplete weight based on multi-granularity linguistic label," Information Sciences, vol. 212, pp. 15-32, Dec. 2012. doi: 10.1016/j.ins.2012.05.011. [Online]. Available: http://linkinghub. elsevier.com/retrieve/pii/S0020025512003556

[27] A. Arasteh, A. Aliahmadi, and M. M. Omran, "A Multi-stage Multi Criteria Model for Portfolio Management," Arabian Journal for Science and Engineering, vol. 39, no. 5, pp. 4269-4283, May 2014. doi: 10.1007/s13369-014-0987-9. [Online]. Available: http://link.springer.com/10.1007/s13369-014-0987-9

[28] J. Wątróbski and W. Sałabun, "Green Supplier Selection Framework Based on Multi-Criteria Decision-Analysis Approach," in Sustainable Design and Manufacturing 2016, R. Setchi, R. J. Howlett, Y. Liu, and P. Theobald, Eds. Cham: Springer International Publishing, 2016, vol. 52, pp. 361-371. ISBN 978-3-319-32096-0 978-3-319-32098-4. [Online]. Available: http://link.springer.com/10.1007/978-3-319-32098-4_31

[29] D. Kannan, K. Govindan, and S. Rajendran, "Fuzzy Axiomatic Design approach based green supplier selection: acase study from Singapore," Journal of Cleaner Production, vol. 96, pp. 194-208, Jun. 2015. doi: 10.1016/j.jclepro.2013.12.076. [Online]. Available: http://www.sciencedirect.com/science/article/pii/S095965261300930X

[30] T. L. Saaty, "Decision making with the analytic hierarchy process," International Journal of Services Sciences, vol. 1, no. 1, pp. 8398, Jan. 2008. doi: 10.1504/IJSSci.2008.01759. [Online]. Available: https://www.inderscienceonline.com/doi/abs/10.1504/IJSSci.2008.01759

[31] C. Macharis, J. Springael, K. De Brucker, and A. Verbeke, "PROMETHEE and AHP: The design of operational synergies in multicriteria analysis.: Strengthening PROMETHEE with ideas of AHP,' European Journal of Operational Research, vol. 153, no. 2, pp. 307-317, Mar. 2004. doi: 10.1016/S0377-2217(03)00153-X. [Online]. Available: http://www.sciencedirect.com/science/article/pii/S037722170300153X

[32] C.-L. Hwang, Y.-J. Lai, and T.-Y. Liu, "A new approach for multiple objective decision making," Computers \& Operations Research, vol. 20, no. 8, pp. 889-899, Oct. 1993. doi: 10.1016/0305-0548(93)90109V. [Online]. Available: http://www.sciencedirect.com/science/article/pii/ 030505489390109V

[33] W. Sałabun, "The characteristic objects method: A new distance-based approach to multicriteria decision-making problems," Journal of MultiCriteria Decision Analysis, vol. 22, no. 1-2, pp. 37-50, 2015

[34] A. Guitouni and J.-M. Martel, "Tentative guidelines to help choosing an appropriate MCDA method," European Journal of Operational Research, vol. 109, no. 2, pp. 501-521, Sep. 1998. doi: 10.1016/S03772217(98)00073-3. [Online]. Available: http://www.sciencedirect.com/ science/article/pii/S0377221798000733

[35] B. Roy and D. Vanderpooten, "The European school of MCDA Emergence, basic features and current works," Journal of Multi-Criteria Decision Analysis, vol. 5, no. 1, pp. 22-38, Mar. 1996. doi 10.1002/(SICI)1099-1360(199603)5:1<22::AID-MCDA93>3.0.CO;2F. [Online]. Available: https://onlinelibrary.wiley.com/doi/abs/10. 1002/\%28SICI\%291099-1360\%28199603\%295\%3A1\%3C22\%3A\% 3AAID-MCDA93\%3E3.0.CO\%3B2-F 